\title{
o El papel mediático del ídolo futbolístico en Latinoamérica: un estudio de caso
}

\author{
Sirio López Velasco
} Universidade Federal do Rio Grande

Resumen: En este trabajo defendemos la tesis de que en sociedades sometidas a repetidas crisis, la gran prensa trata de inculcar a buena parte de la sociedad, golpeada en su autoestima, la doble ilusión de que es valiosa en la figura de un héroe deportivo millonario, y de que el fútbol puede permitir a sus hijos el acceso al círculo de los ricos y famosos.

Abstract: In the following paper, I defend the thesis that, in societies that suffer continuous crisis that hurt the self-confidence of the population, the main press tries to sell its readers the double illusion of partaking the glamour of the sport idols and that their children, through a sport career, may attain the club of the rich and famous.

Palabras clave: Fútbol, ídolo deportivo, capitalismo, ecomunitarismo, América Latina.

Keywords: Football, sport' idols, capitalism, ecommunitarianism, Latin America.

\section{Introducción}

En estas breves líneas aborda- de un futbolista-símbolo como lo es remos de forma introductoria el tema del papel que hace jugar hoy la gran prensa al héroe deportivo latinoamericano, especialmente en el fútbol que es el principal deporte de masas en nuestro continente. Para ello nos concentraremos en el caso el del uruguayo Luis Suárez (quien hace poco más de una temporada juega en el Fútbol Club Barcelona, considerado uno de los mejores del mundo por la calidad del juego que exhibe, y también por su riqueza); quedará en los interesados saber si 
lo aquí dicho se aplica o no a lo que ocurre en sus países (especialmente en América Latina) con algún otro futbolista (o deportista). Aclaro por las dudas que si bien el deporte colectivo que practiqué con mejor éxito fue el básquetbol, me encanta mirar fútbol (y lo hago preferentemente en la TV.); aclaro también que la muestra de datos que me sirve de apoyo fue extraída de noticias de un diario de la gran prensa uruguaya a lo largo de un mes (entre principios de enero y principios de febrero de 2016). La tesis que defenderé es bastante obvia, pero no por ello deja de tener valor, sobre todo cuando se enmarca en el contexto capitalista en el que se inscribe hoy el fútbol profesional (y muchos otros deportes), particularmente en el contexto del capitalismo latinoamericano; nos referimos al hecho de que en sociedades que no se destacan en el mundo por hazañas económicas, científicas, tecnológicas y/o militares, y donde las crisis permanentes o periódicas mantienen deprimida y/o en vilo a una mayoría popular afectada en su autoconfianza, esos ídolos son usados por la gran prensa en un doble sentido: por un lado para intentar inculcar a la ciudadanía la creencia ilusoria de que "por lo menos en algo todos los de este país somos muy buenos, e inspiramos el reconocimiento y el respeto del mundo, incluso en los países económicamente, políticamente y militarmente más poderosos", y también para fomentar la esperanza ilusoria que los pobres, marginados y desesperados tienen de que el fútbol, si no para ellos por lo menos para sus hijos, realice el sueño capitalista de elevarlos al reducido círculo de los "ricos y famosos".

\section{Los datos}

Todos los datos relativos a Luis Suárez fueron adquiridos vía internet del diario uruguayo El País, tradicional diario de derecha que contiene el conocido suplemento deportivo "Ovación", ambos están disponibles en internet. Veamos algunas de las notas consagradas a Suárez en el período considerado, yendo de una jornada en la que el Barcelona no obtuvo la victoria, hasta el día siguiente en una apoteósica exhibición de Suárez ante el Valencia en la semifinal de la Copa de España, en la que el delantero uruguayo marcó cuatro goles. El 5 de enero de 2016, volviendo al entonces reciente empate a cero con el Espanyol, por el Campeonato español, el titular anuncia "El tridente no siempre triunfa", y antes de dar paso al video explicativo incluye el siguiente subtítulo: "La falta de gol y el juego brusco del Espanyol hizo que el tridente se secara. Lionel Messi, Luis Suárez y Neymar tuvieron un partido con más protestas que juego". Creo que aquí vale la pena destacar que el texto 
sugiere (por el "no siempre...") que Suárez integra un equipo (y en especial un trío de ataque) casi invencible, lo que de por sí le da valor de superhéroe al jugador uruguayo; además, se sugiere que cuando no logra vencer, la culpa es de la brusquedad de los adversarios y de su maña para enredar el juego hasta convertirlo en una sesión de protestas. Hay que recordar aquí que con esa aproximación el texto pretende sacar a Suárez de la condición de culpable de juego ilícito al que lo redujo buena parte de la gran prensa y la opinión deportiva mundial tras morder al defensor italiano Chiellini en la Copa del Mundo disputada en Brasil en 2014 (y haber recibido una enorme sanción de la FIFA a causa de ese episodio), para ponerlo en la condición de víctima de adversarios desleales. Ahora bien, tan sólo un día después, el 6 de enero de 2016, y al referirse al nuevo partido contra el Espanyol (ahora por la Copa del Rey, en el cual el Barcelona venció por 4 a 1), disputado menos de una semana luego del anterior, el diario se ve obligado a reflotar la mala fama de Suárez al noticiar que el juez de ese partido escribió en su informe:

Al finalizar el encuentro y una vez en el túnel de vestuarios, el dorsal $N^{\circ} 9$ del FC Barcelona, D. Luis Alberto Suárez Díaz, mientras todos los jugadores del RCD Espanyol subían las escaleras del túnel de vestuarios, les esperó y se dirigió a ellos repitiendo en varias ocasiones lo siguiente: "Aquí os estoy esperando, venid acá; Sos un desecho", provocando con esto un enfrentamiento entre jugadores de ambos clubes, debiendo intervenir el personal de seguridad allí presente, así como los cuerpos técnicos de ambos equipos.

Y el diario anunció que Suárez podía sufrir una sanción a causa de ese episodio. No obstante, un día después, el diario sale otra vez en defensa de Suárez, titulando:
"El juez se habría equivocado: Suárez no sería el de la provocación”, y basa esa defensa en supuestos testigos, noticiando que:

\section{(...) este jueves algunos medios españoles, entre ellos Sport y Mundo Deportivo, afirman que el futbolista que expresó dichas palabras fue Javier Mascherano y no Luis Suárez, aunque el "Pistolero" (N.B. uno de los apodos de Suárez) también se encontraría en el túnel junto con el argentino, Neymar y Munir.}

Hay que notar que ese intento de inocentar a Suárez ya se había mani- festado cuando ocurrió su sanción mundialista, pues llegó a decirse en 
ese mismo diario, en un principio, que la agresión contra Chiellini no habría ocurrido, y luego se trató de maquillarla con supuestas maniobras de Brasil y de la FIFA dirigidas a tratar de eliminar a Uruguay de esa competencia.

De hecho, y aunque Suárez negó la autoría de las ofensas verbales y físicas, fue suspendido por dos partidos de la Copa de España. El
Barcelona apeló a la sanción sin éxito. En el partido de vuelta por la Copa contra el Espanyol (con Suárez ausente por la sanción recibida), la hinchada de este último no dejó de marcar su condena desplegando en la tribuna un enorme cartel con las palabras "Suárez ladrador y mordedor". Ahora el Barcelona triunfó por 2 a 0 , y el diario dice que el clima fue similar al del partido anterior, reportando:

\begin{abstract}
Dentro de la cancha hubo varios cruces entre los jugadores, en situaciones de juego y que continuaron luego de que el juez sancionara. Pero la situación más polémica se dio en la tribuna de Espanyol. El sector más bullicioso de la hinchada "Periquita" demostró que la espina de la ida estaba clavada y deseaban descargarse con los jugadores "Culé". A lo largo del encuentro mostraron pancartas provocadoras dirigidas a distintos jugadores y hacia la institución "Blaugrana".
\end{abstract}

Con ese enfoque, el diario pretendía una vez más sacar el peso de la eventual culpa por los sucesos anteriores de la espalda de Suárez, y cargárselo al club adversario (ahora incluyendo a su hinchada). Mas ya antes de ese partido el diario había enaltecido a Suárez (por lo menos esa era su intención) estampando en un titular "El director de Hollywood fanático de Suárez y de Peñarol”, refiriéndose a "Michael Apted, director de franquicias como James Bond o Narnia y el film Gorilas en la Niebla, (quien) está en Punta del Este y habló de su otra pasión: el fútbol. Declaró su fanatismo por el delantero uruguayo". Se nota que aquí (y en un momento en el que Suárez volvía al papel de villano) el diario trata de mostrar cómo el jugador es admirado por un gran personaje de una de las entidades más admiradas del mundo, a saber la máquina de cine hollywoodiana; la intención radica en mostrar que, a pesar de pequeño, el Uruguay logra a través de Suárez y de uno de sus dos clubes de fútbol más importantes (Peñarol) ser admirado por uno de los exponentes de la mundialmente famosa y poderosa meca del cine. La noticia tiene un plus de afirmación de la autoestima uruguaya porque el elogio viene de una figura no vinculada al deporte, y sí al medio "cultural" en sentido amplio; y ello es importante para hacer frente 
anticipadamente a aquellos eventuales críticos que menosprecien el fútbol ( $\mathrm{y} / \mathrm{o}$ el deporte en general) como actividad digna de encomio.

El 18 de enero de 2016, hablando del partido por el Campeonato (en el que Suárez jugó) contra el Athletic de Bilbao, el diario titula: "Suárez en la pelea por la Bota de Oro. El delantero del Barcelona, que con sus tres goles de este domingo quedó como máximo goleador de España, se metió entre los delanteros con más goles de toda Europa". Aquí la idea dominante es reforzar la dignificación de Suárez (y por su intermedio la del pequeño pueblo uruguayo) haciendo notar que sus logros y fama no se restringen al perímetro de la geografía española, sino que la trascienden ampliamente para abarcar a toda Europa. Ahora bien, hay que saber que la sociedad uruguaya hasta la Segunda Guerra Mundial (particularmente en las referencias de sus estadistas, en su sistema educativo y en su vida cultural) vivió encandilada por la civilización europea (antes de dividir esa admiracióndependencia con la nueva potencia: los EE.UU.); esa realidad llevaba a que los estudiantes de enseñanza media uruguaya fuesen entonces sistemáticamente introducidos al inglés, el francés o el alemán, pero nunca tuvieron en esa época ni una disciplina sistemática de portugués, a pesar del fronterizo y gigante Brasil, y mucho menos de las lenguas indígenas que eran habladas por amplias mayorías en los cercanos Paraguay y Bolivia, como lo son el guaraní, por un lado, y el quechua y el aymara, por otro, respectivamente; hay que registrar que en su europeo-dependencia las clases alta y media uruguayas (y quizá también parte de sus clases bajas) partían del hecho de que en Uruguay las últimas comunidades indígenas organizadas habían sido exterminadas a mediados del siglo XIX, y que en el país circulaba la boutade de que los uruguayos descendían de los barcos (o sea de los inmigrantes europeos, y no de ninguna etnia indígena). Esos datos sirven para entender mejor la importancia que le concede el diario al reconocimiento europeo de Suárez, y el diario extiende esa bocanada de reafirmación de la autoestima al continente cuando dice en esa misma nota que: "los futbolistas latinoamericanos siguen destacando en el fútbol europeo" (refiriéndose a la buena campaña del goleador argentino Gonzalo Higuaín en el fútbol italiano).

El 23 de enero de 2016, el diario informa acerca de la victoria 2 a 1 contra el Málaga, y afirma que el tridente ofensivo del Barcelona "quedó reducido a Messi y al uruguayo Luis Suárez que dio un pase de la muerte a Munir a poco de comenzar el partido para poner en ventaja al Barcelona". Ese registro sirve para mantener en alto el prestigio del compatriota, aun cuando no marca ningún gol. 
Al día siguiente, el diario vuelve a la carga en lo relativo al prestigio internacional de Suárez (y por ende, supuestamente, de su país y sus cote- rráneos) cuando da cuenta del reconocimiento que en las redes sociales le prodigó su muy mediático compañero de equipo, Neymar, al estampar:

\section{Neymar saludó a Luis Suárez por su cumpleaños número 29. "Feliz cumple mi gordito... iMuchas felicidades siempre hermano! Eres un crack como jugador y mucho más como persona... Te admiro", puso el brasileño en las redes sociales.}

La noticia es aún más regocijante para la estima nacional cuando se sabe que desde el Mundial de Fútbol donde Uruguay le ganó a Brasil en su propia tierra en 1950, hay una gran rivalidad deportiva entre ambos países (que en los últimos años se ha saldado casi siempre en favor de los brasileños, ya que Uruguay nunca más pudo conquistar otro Mundial, mientras que Brasil ya logró cinco desde aquella fecha); ahora, quien elogia a Suárez es precisamente un brasileño. Ya que aludimos a Maracaná, permítaseme divergir ni más ni menos que con el capitán de aquel mítico equipo uruguayo, Obdulio Varela, cuando muchos años después de aquel triunfo declaró que en Maracaná lo que se vio fue que el jugador uruguayo no admite perder; creo que ese concepto es infeliz, porque puede transmitir la idea de que esa negativa a todo costo de la derrota incluye el uso de cualquier tipo de comportamiento ilegítimo para evitarla. Si vemos los números de aquel partido se constatará que esa ocasión Brasil cometió más faltas que Uruguay, o sea que jel cuadro uruguayo jugó más limpio! Así no se puede compartir la frase de Obdulio, quien le daría incluso una disculpa a Suárez por su mordida a Chiellini (la que, dicho sea de paso, fue condenada por el héroe-goleador uruguayo de Maracaná, Alcides Ghiggia, quien declaró inmediatamente a lo sucedido que "habría que revisarle la cabeza a ese muchacho, pues algo anda mal ahí", palabras más, palabras menos); por mi parte creo que la hazaña de Maracaná inculcó a muchísimas uruguayas y a muchísimos uruguayos, hasta hoy, la idea de que aunque se pueda perder ( $y$ admitir la derrota) antes del pleito nunca se resigna la victoria, ni se admite que ningún contrario sea imbatible; esa sabia máxima llevada a todos los ámbitos de la vida (en la que las adversidades no son necesariamente sólo o exclusivamente humanas, sino que pueden deberse también a obstáculos naturales y/o circunstancias imprevistas), no disculpa la falta de Suárez, y sirve para fortalecer el carácter de la actual y futuras generaciones de uruguayas y uruguayos.

El 27 de enero de 2016, el diario da cuenta de que el Barcelona 
accedió a las semifinales de la Copa al batir nuevamente al Athletic de Bilbao por 3 a 1,y explica que Suárez es co-responsable del éxito: “... en la segunda mitad Luis Suárez, Gerard Piqué y Neymar le dieron la vuelta a la situación y llevaron a los azulgranas a su novena semifinal en diez años"; y aclara por qué el uruguayo no pudo ser decisivo antes: "Suárez estaba demasiado solo ante los dos centrales del Athletic..."; o sea que si no pudo decidir antes fue porque le faltó la obligada ayuda de sus pares, hacia quienes se desvía la "culpa".

Pero el 31 de enero de 2016, comentando el triunfo por el campeonato ante el Atlético de Madrid, el diario titula "Luis le dio el triunfo y la punta al Barça"; hay que notar en ese titular que se le adjudica el mérito del triunfo y de la punta del campeonato exclusiva y únicamente al uruguayo (aunque el propio Suárez en sus declaraciones no se cansa de destacar los méritos de todo el equipo tras cada victoria); ese enfoque es una manera más de reforzar la autoconfianza uruguaya, elevando a la categoría de superhéroe solitario-todopoderoso a un compatriota. Luego en su comentario agrega el diario:

El salteño dio nuevamente la victoria a su equipo en un partido importantísimo para el devenir de la Liga española (...) En una de sus jugadas patentadas, Suárez aguantó el empellón y cruzó la pelota por entre las piernas del cuidavallas. Fuerza, velocidad y marca sobre el hombre (...) Luis Suárez festejó el triunfo con sus compañeros. Igualó con 31 goles su mejor temporada en el Liverpool y le sacó dos de ventaja a Benzema en la tabla de artilleros.

De paso se registra, insistiendo otra vez en la dimensión europea del éxito de Suárez (y, supuestamente del país que representa), que esta hazaña sigue a otra lograda antes en Inglaterra.

Finalmente (para el período que elegimos para el análisis del mencionado diario), el 4 de febrero de 2016, tras los cuatro goles marcados por Suárez al Valencia en el partido de ida de la semifinal de la Copa de España, el periódico estampa la siguiente pregunta: " ¿Es el mejor ' 9 ' del mundo?". Ahora, como se ve, también Europa queda chica, y el contexto digno del éxito de Suárez (y de la autoconfianza uruguaya) es el mundo entero. 


\section{Un breve análisis de conjunto}

Deduzco del análisis que hizo Fromm (1955, cap. VII) de la idolatría autoritaria que hay en la masa que sigue al dictador la ilusión-impresión-convicción de que es poderosa a través del poder del Führer. En el caso que ahora analizamos creo que se reproduce un fenómeno análogo. El diario pretende que buena parte de la población entera de un país (en este caso del Uruguay pequeño y desdeñable por su potencia económica, política y militar), angustiada por su situación precaria de vida, venza ilusoriamente (sin cambiar nada en la realidad) su sensación de impotente insignificancia al verse representada por alguien que capta la admiración del mundo y es millonario. Es notable que según noticia televisiva, en el actual México dominado por la violencia cotidiana del narcotráfico, las estadísticas mostraron que el número de delitos disminuía los días en los que jugaba en Europa el futbolista mexicano "Chicharito" Hernández. La gran prensa capitalista intenta que, a través de ese héroe, esa población se autoperciba como valiosa, al punto de merecer la admiración mundial, sin cambiar nada en la realidad capitalista que la agobia; y, simultáneamente, trata de que esa población, viéndose en el ejemplo individual del héroe millonario, sueñe para sus hijos un futuro semejante al del personaje en cuestión (otra vez, sin alterar nada en la realidad social que la cerca). Dicha mayoría no sabe o no quiere saber los datos de la cruda realidad, a saber, por ejemplo que en el caso de un país tan futbolero como Brasil, todas las fuentes dicen que tan sólo el uno por ciento de los futbolistas profesionales (ni hablemos del total de practicantes de ese deporte) logra vivir del fútbol con cierta holgura (mientras el $99 \%$ restante no se distingue mucho en sus entradas de lo que recibe un obrero). Por todo ello, alguien dijo que en Uruguay el fútbol era el opio del pueblo.

\section{El fútbol en el contexto del capitalismo (latinoamericano y mundial)}

Hace tiempo que el fútbol profesional se ha transformado en un gran negociado (como lo atestiguan los recientes escándalos de corrupción y financieros de la FIFA, y los sucesivos casos de manipulación de resultados vinculados a las mafias de las apuestas). Si ese hecho se admite por la gran prensa, lo que no se dice es que en ese contexto los clubes y los futbolistas pasan a ser simples mercancías, y como tal son tratados. A tal punto llega la mercantilización y fragmentación del futbolista profesional que en América Latina es común que la propiedad de esos 
atletas esté compartida, como una "pizza", por varios dueños, a quienes su persona pertenece a los efectos del reparto de los lucros de los precios de los traspasos y contratos. Todo eso significa que el futbolista (aunque sea un millonario del $1 \%$ exitoso), de forma similar a lo que le sucede a cualquier otro asalariado, está alienado (ver López Velasco, 2009): a) del "trabajo" (o sea, tiene que luchar a brazo partido para hacerse un lugar en un club profesional, y al término de su contrato puede ser despedido sin más); b) de su actividad "productiva" (pues debe hacer lo que su patrón y entrenador le manden); c) de la naturaleza (pues no mantiene con la naturaleza no humana ninguna interacción productiva en sentido estricto); d) de los otros (pues lucha contra la competencia de sus pares para conquistar y mantener su puesto); y e) de sí mismo (pues no se realiza como individuo universal en todas sus potencialidades $y / 0$ vocaciones, ya que debe dedicarse integralmente a su tarea de futbolista; esa visible unilateralización hizo que el semanario uruguayo Marcha hace muchos años publicara una caricatura de Pelé, entonces en el auge de su carrera, representando una figura humana cuya cabeza era un zapato de fútbol; la proverbial ignorancia de muchos futbolistas famosos fue ejemplificada en Brasil con la confusión del célebre "Garrincha", cuando creyó que la ciudad brasileña de Belém do Pará, donde iría a jugar, era "la cuna de Nuestro Señor Jesucristo”).

\section{Imaginando un fútbol (y un deporte) educativo-cooperativo con espíritu ecomunitarista}

Hemos caracterizado al ecomunitarismo como el orden socioambiental poscapitalista utópico (pero indispensable horizonte-guía para que la acción actual-futura tenga un sentido claramente definido) capaz de funcionar en su día a día con base en las tres normas fundamentales de la ética (que nos exigen, respectivamente, luchar para realizar nuestra libertad individual de decisión, realizar esa libertad en búsquedas de respuestas consensuales con los otros, y preservar-regenerar la salud de la naturaleza humana y no humana); sostengo que esas tres normas sólo son realizables plenamente en una sociedad sin clases.

Hacen parte del ecomunitarismo: a) una economía ecológica y sin patrones que aplique el lema "de cada uno según su capacidad y a cada uno según su necesidad (re-definida con base en las tres normas éticas básicas), respetando los equilibrios ecológicos"; b) una educación ambiental ecomunitarista; c) una política de todos (basada en la democracia participativa, siempre que sea posible y directa); d) una comunicación simétrica (que ponga 
en manos de las comunidades los medios actualmente controlados por los latifundios mediáticos); e) una erótica de la liberación (que defienda el libre disfrute consensuado del placer compartido y combata el machismo y toda discriminación causada por opciones sexuales); y f) una vida comunitaria pactada con base a Cuasi Razonamientos Causales, y por ende, superadora de la Moral y del Derecho Positivo (en todo lo que sea posible, ver López Velasco, 2009). En el ecomunitarismo florece al individuo universal en el seno de una comunidad solidaria.

Ahora bien, es fácil constatar que en el fútbol (y el deporte) mercantilizado se atenta contra las tres normas básicas de la ética; contrariando a la primera, la libertad personal del atleta queda atada a sus dueños y entrenadores; contrariando a la segunda, no se practica una actividad cooperativa y consensualmente organizada-desarrollada; y contrariando a la tercera norma, en la actividad efectivamente practicada se pone en riesgo la salud de la naturaleza humana (y también no humana en algunos deportes devastadores $\mathrm{y} / \mathrm{o}$ contaminantes del medio ambiente), por doping y/o lesiones debidas a esfuerzos exagerados; el doping crónico del supercampeón de ciclismo Lance Armstrong, descubierto en 2012, es un ejemplo mayúsculo de esto último. Así en el fútbol (y el deporte) sometido al capitalismo, los individuos son sacrificados al dios del lucro, y el espíritu comunitario sucumbe ante la glorificación del individualismo egoísta.

En contrapartida, podemos enunciar como principios del deporte educativo-cooperativo en perspectiva ecomunitarista los siguientes (ver López Velasco, 2015): 1) nunca será practicado por dinero; 2) priorizará la cooperación (fundamentada en la segunda y primera norma de la ética), o sea, la actividad consensual basada en la libertad de contribución de cada uno); y 3) siempre velará por el respeto a la tercer norma de la ética, o sea por la preservaciónregeneración de la salud de la naturaleza humana y no humana; así se fomentará la actividad que promoverá tal salud y se luchará contra (incluso mediante la prohibición) las actividades que intrínsecamente implican lastimar a otros participantes (como ocurre en el box y deportes semejantes a él).

Algunos juegos de niños, con reglas creadas $y / 0$ reinventadas cooperativamente (ver Piaget, 2003), son bellos ejemplos de deporte educativo y cooperativo que pueden ser reivindicados por la propuesta ecomunitarista; en efecto, ellos incentivan el desarrollo de un cuerpo sano en un ambiente de confraternización, en el cual el niño aprende el valor de la camaradería, del esfuerzo colectivo e, incluso, del 
sacrificio en pro de los demás; claro que es importante saber criticar y no incentivar otros juegos de niños que incluyen el espíritu competitivo y de oposición entre individuos $y / 0$ grupos, propio del capitalismo. (Hay que recordar que se dice que -para no provocar conflictos intergrupales- los aztecas practicaban una modalidad de juego colectivo de pelota que necesariamente debía terminar empatado).

Y en la óptica ecomunitarista también podemos delinear una reformulación del fútbol (también generalizable, con las debidas adaptaciones, a otros deportes, incluyendo los practicados por adultos) adoptando, por ejemplo (entre otras posibles con el mismo espíritu) las siguientes reglas: 1 ) de los goles que marque cada equipo en un partido, será contabilizado solamente uno de cada jugador (lo que obliga a que el equipo se esfuerce para que todos sus integrantes marquen su gol; si un jugador marca un segundo tanto personal, éste no será contabilizado); 2) en equipos de hasta 6 jugadores, solamente será válido aquel gol que suceda después de que en la jugada que lo originó todos los jugadores del equipo hayan tocado la pelota (para fomentar el juego colectivo-cooperativo); se admite solamente una "interrupción" por el toque de algún adversario, y si el mismo hizo dos se debe recomenzar el conteo de los toques); para equipos de 11 jugadores o más, se puede fijar la regla de que para que un gol sea válido por lo menos la mitad de los jugadores del equipo que lo marca hayan debido tocar la pelota (valiendo la regla de la "interrupción” antes citada); y 3) habrá rotación en la posición del portero y de todas las posiciones de defensa y ataque tras cada gol válido (para fomentar el desarrollo de múltiples habilidades).

\section{Referencias}

- Fromm, E. (1955). The sane society. (En español: Psicoanálisis de la sociedad contemporánea, 1956). México: Fondo de Cultura Económica.

- López Velasco, S. (2015). Notas sobre ecomunitarismo e esporte educativo e cooperativo. Revista Diaphonia $N^{0} 1$, pp. 155-168, Toledo (PR): ed. UNIOESTE. Consultado en junio de 2015. Recuperado de http://e-revista. unioeste.br/index.php/diaphonia . (2009). Ética ecomunitarista. San Luis Potosí, México: UASLP.

- Ovación. (Enero-febrero de 2016). Suplemento deportivo de El País. Uruguay. Recuperado de:

- Piaget, J. (2003). Le jugement moral chez l'enfant. (1ºublicación de 1932). París, Francia: PUF. 